\title{
Gasification of Nickel-Preloaded Oil Palm Biomass with Air
}

\author{
Syed Shatir A. Syed-Hassan*, Siti Nor Izuera Nor-Azemi \\ Faculty of Chemical Engineering, Universiti Teknologi MARA, 40450 Shah Alam, Selangor, \\ Malaysia
}

Received: $12^{\text {nd }}$ September 2015; Revised: $10^{\text {th }}$ January 2016; Accepted: $16^{\text {th }}$ January 2016

\begin{abstract}
This study experimentally investigates the gasification of nickel-preloaded oil palm biomass as an alternative catalytic approach to produce clean syngas. To eliminate the use of catalyst support, nickel was added directly to the oil palm mesocarp fiber via ion-exchange using an aqueous solution of nickel nitrate. Nickel species was found to disperse very well on the biomass at a nano-scale dispersion. The presence of the finely dispersed nickels on biomass enhanced syngas production and reduced tar content in the producer gas during the air gasification of biomass. It is believed that nickel particles attached on the biomass and its char promote the catalytic cracking of tar on their surface and supply free radicals to the gas phase to enhance the radical-driven gas-phase reactions for the reforming of high molecular weight hydrocarbons. The unconsumed nickel-containing char shows great potential to be re-utilised as a catalyst to further enhance the destruction of tar components in the secondary tar reduction process. Copyright (C) 2016 BCREC GROUP. All rights reserved
\end{abstract}

Keywords: gasification; biomass; oil palm mesocarp fiber; nickel; tar

How to Cite: Syed-Hassan, S.S.A., Nor-Azemi, S. (2016). Gasification of Nickel-Preloaded Oil Palm Biomass with Air. Bulletin of Chemical Reaction Engineering \& Catalysis, 11 (3): 262-272 (doi:10.9767/bcrec.11.3.566.262-272)

Permalink/DOI: http://doi.org/10.9767/bcrec.11.3.566.262-272

\section{Introduction}

Gasification is an attractive technology for exploiting the abundantly available biomass materials as the renewable sources of energy and fuels. The presence of incompletely reformed volatiles (tar) in the producer gas, however, causes several problems to the biomass gasification systems. Tar which is a complex compound, consisting a mixture of hundreds of heavy organic constituents including aliphatic and aromatic hydrocarbons as well as oxygenates, does not only lower the heating value of

* Corresponding Author.

E-mail: shatir@salam.uitm.edu.my; syedshatir@gmail.com (S.S.A. Syed-Hassan) +60355436344, Fax: +60355436300 fuel gas but may also condense at various process stages to cause clogging, fouling, corrosion, loss of efficiency and unscheduled plant shutdown.

Physical gas clean up (e.g. filtration and scrubbing) can be used to remove tar. However, this strategy requires gas cooling that result in the wastage of large amount of heat. In addition, considerable amount of wastewater is also produced, necessitating an additional treatment in the process system which in turn leads to increased capital and operating costs. Thermal process of tar reforming, on the other hand, requires an operation at a highly elevated temperature (above $1100{ }^{\circ} \mathrm{C}$ ) for effective tar destruction.

Catalytic process appears as a promising alternative to the physical and thermal processes 
from both economic and technical points of view. The conversion of tar using catalyst can be achieved at temperatures below $1000^{\circ} \mathrm{C}$, offering at the same time the advantages of improving the yield of synthesis gas and eliminating the needs for tar collection and disposal. Generally, the catalytic tar reduction can be carried out using two approaches: (i) the primary method in which the catalysts are mixed together with the feed biomass or act as bed materials where the tar is cracked/reformed inside the gasifier itself or (ii) the secondary method where the tar is treated inside a secondary catalytic reactor downstream of the gasifier.

Various types of catalyst, including natural minerals, alkali metals, Ni-based catalysts, and noble metals, have been examined for their suitability in reducing biomass gasification tar. A number of reviews [1-3] have been made to summarise the potentials and limitations of these catalysts. The Ni based catalysts are very promising due to their high activity and reasonable cost. Indeed, Ni-based catalysts are widely available as they are commercially employed in the petrochemical industry for methane and naphtha reforming [3]. When applied in biomass gasification, the Ni-based catalyst may not only catalyse the destruction of tar but can simultaneously reform light hydrocarbons to improve the syngas content [2-3]. Some studies also report that Ni-based catalysts can effectively reduce $\mathrm{NO}_{\mathrm{x}}$ emission during biomass gasification [4-5].

Majority of commercial nickel catalysts are supported by porous catalyst supports (e.g. $\mathrm{SiO}_{2}, \mathrm{Al}_{2} \mathrm{O}_{3}$, and $\mathrm{MgO}$ ) in order to provide wide surface area for dispersion of active phase so as to increase the catalyst activity and stability [3]. There are, however, some drawbacks with the use of the traditional Ni-supported catalysts. The cost of support materials and the complicated methods of production add substantially to the cost of commercial nickel catalysts. During the gasification, only nickel particles at the exterior of support are available for contact with hydrocarbon vapour. The polymerisation of hydrocarbon vapour, leading to carbon deposition inside the rigid porous structure of the supported-catalyst, blocks the access of biomass volatiles and gasifying agent to the catalytic active sites in the interior of catalyst particles, causing an inefficient use of the catalyst as well as leading to shortened catalyst life time.

Recent studies show that nickel can be dispersed on the biomass at a nanometer scale, similar to the dispersion on the conventional support materials [6-7]. If the nickel-loaded biomass is gasified, the contacts between biomass volatiles and the active catalytic sites can be improved significantly. Nickel sites are available immediately for contact with the nascent volatiles upon biomass decomposition without the complicated intra-particle mass transfer barriers (usually associated with other supported nickel catalysts). The attachment of nickel directly to the biomass simplifies the catalyst preparation steps and completely eliminates the need of catalyst support to result in the lower capital/operating costs and environmental impacts. The Ni-containing char remaining as a residue in the gasifier can be reutilised as a catalyst by either mixing with feed biomass or used in the secondary catalytic tar reduction process.

We report here our study examining the gasification of oil palm biomass with pre-loaded nickel as an alternative to the conventional approach of catalytic biomass gasification using supported catalyst. Nickel was pre-loaded to oil palm mesocarp fiber (OPMF) by soaking in nickel nitrate solution. The Ni-preloaded OPMF was gasified using air as the gasifying agent. The produced Ni-containing char was reutilised to catalyse steam reforming of tar model compounds in order to evaluate its potential re-utilisation as a catalyst in the real integrated biomass gasification system.

\section{Materials and Methods}

\subsection{Biomass preparation and nickel ad- sorption study}

OPMF (obtained from Sime Darby R\&D Centre, Carey Island, Malaysia) was sundried for two days and further dried in an oven for 24 $\mathrm{h}$ at $110{ }^{\circ} \mathrm{C}$ in order to remove the moisture and to preserve from biological degradation. The dried OPMF was ground using a cutting mill and sieved to obtain particle size of 125 $300 \mu \mathrm{m}$. The sieved OPMF was stored in tight containers and placed in a refrigerator until further use.

Nickel solution was prepared by dissolving $10 \mathrm{~g}$ of $\mathrm{Ni}\left(\mathrm{NO}_{3}\right)_{2} .6 \mathrm{H}_{2} \mathrm{O}$ (Merck) in $1200 \mathrm{~mL}$ distilled water. Ground OPMF of about $200 \mathrm{~g}$ was added into the nickel solution and the mixture was stirred with a magnetic stirrer for 120 min. The mixture was then filtered and washed with distilled water several times until the filtrate achieved a constant $\mathrm{pH}$. To determine the concentration of nickel in the OPMF and its char, the solid samples were acid digested in a microwave digester (Milestone ETHOS) and analysed using an inductively 
coupled plasma optical emission spectrometer (ICP-OES, iCAP 6000 Series).

\subsection{Air gasification of OPMF}

OPMF (with and without $\mathrm{Ni}$ addition) was gasified inside a stainless steel reactor shown in Figure 1a. The reactor with an inner diameter of $2.2 \mathrm{~cm}$ and a total height of $45 \mathrm{~cm}$ was heated inside a tube furnace. A thermocouple was placed inside the reactor to determine the reactor temperature. The biomass was continuously fed into the reactor from the top using a screw feeder driven by a variable electric motor. Air was introduced into the reactor (from the bottom) as a gasifying agent with the equivalent ratio (ER) of 0.2 and the flow rate of $1.2 \mathrm{~L} / \mathrm{min}$ (controlled by a mass flow controller). The OPMF feeding rate was calibrated 5 times in order to establish a consistent rate of $2.3 \mathrm{~g} / \mathrm{min}$.

Methanol-chloroform mixture (1:4 ratio) was placed inside three fritted dreschel bottles to act as a gas cooler and a tar trapper. The produced gas was passed through these dreschel bottles and the gas samples were collected from the outlet of the last dreschel bottle using gas sampling bags. In every experiment, the gas samples were analysed offline by a ThermoFinnigan gas chromatography (GC) equipped with a thermal conductivity detector (TCD). The measurement was repeated three times using $\mathrm{GC}$ and the average value was taken to represent the gas composition for a particular gas sample.

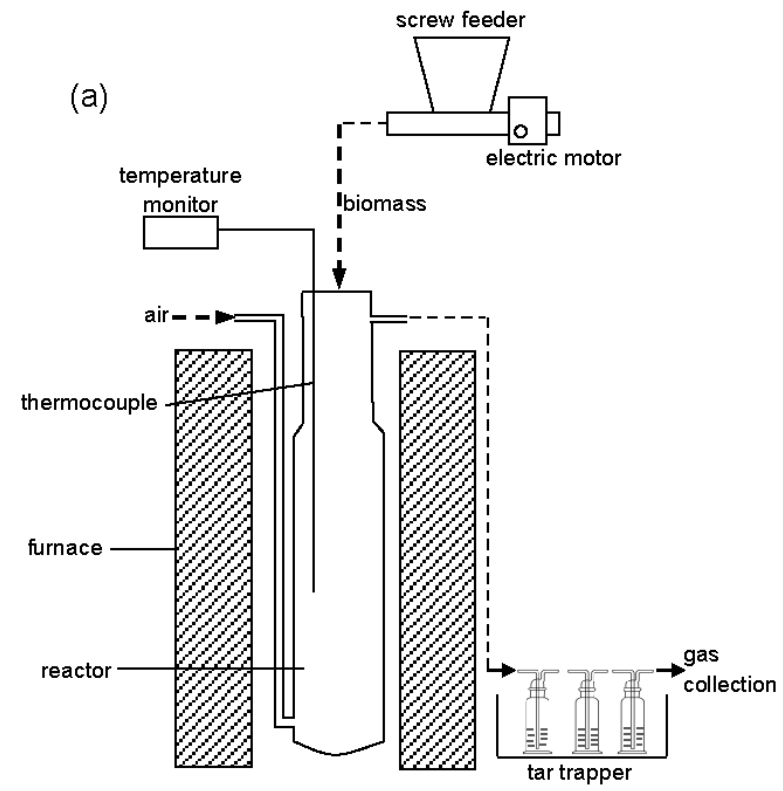

Tar solutions from the three dreschel bottles were collected at the end of the experiments. After mixing them very well, $10 \mathrm{~g}$ of the solution was transferred into a $50 \mathrm{~mL}$ beaker and dried in an oven at $35{ }^{\circ} \mathrm{C}$ for $4 \mathrm{~h}$. The solvent evaporated completely at this temperature, leaving the heavier organic compounds (tar) to remain in the beaker. $10 \mathrm{~g}$ of clean methanol-chloroform mixture was also dried in the same manner as a blank reference. The tar yield was calculated using the following equation:

$$
\operatorname{Tar} \operatorname{Yield}(\%)=\frac{W_{S}\left(W_{t}-W_{b}\right)}{10} \times \frac{100 \%}{W_{F}}
$$

where $W_{t}=$ weight of tar in $10 \mathrm{~g}$ collected tar solution $(\mathrm{g}), W_{b}=$ weight of tar in $10 \mathrm{~g}$ blank solution $(\mathrm{g}), W_{S}=$ total weight of tar solution collected from three dreschel bottles (g), and $W_{F}$ $=$ total weight of OPMF fed into the reactor $(\mathrm{g})$.

\subsection{Steam reforming of tar module com- pounds using Ni-containing char as a catalyst}

Benzene (99\%, System) and toluene (99.9\%, Sigma Aldrich) were used as the tar model compounds to evaluate the potential reutilisation of Ni-containing char as a catalyst for the reforming of tar. Experiments were carried out in a stainless steel fixed-bed reactor at $1 \mathrm{~atm}$ and $850^{\circ} \mathrm{C}$. The reactor with an inner diameter of $2.2 \mathrm{~cm}$ and a length of $40 \mathrm{~cm}$ was used in this study. A schematic diagram of the experimental set-up is shown in Figure 1b.

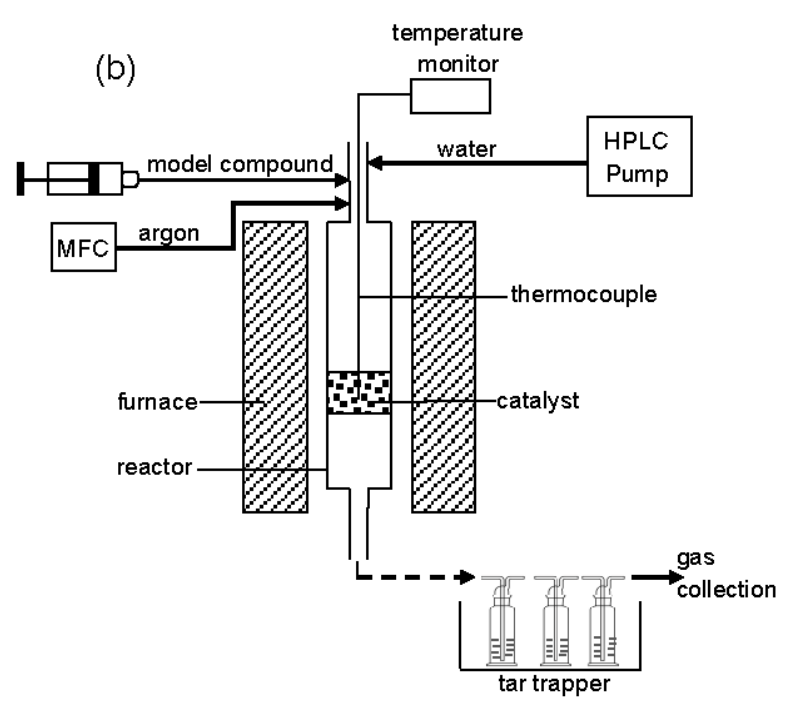

Figure 1. Schematic diagrams of (a) the air gasification reactor and (b) the steam reforming reactor 
The char produced from air gasification of Ni-preloaded OPMF at the temperature of 900 ${ }^{\circ} \mathrm{C}$, from the system described in the previous section, was placed in the catalyst bed of the reactor. Water was injected into the reactor using HPLC pump (Series I Metering HPLC Pump) while benzene or toluene was fed into the reactor using a syringe pump (NE-1000). Argon was used as the carrier gas inside the reactor. The product gas was passed through three dreschel bottles containing methanolchloroform mixture (as described in Section 2.2) before being collected in the gas sampling bags. The gas samples were analysed by the GC to determine the composition of the product gas. Experiments were also performed using gasification char of the untreated OPMF (without Ni addition) as a catalyst as well as in the empty bed condition for comparison purposes.

\subsection{Biomass / char characterization}

The functional groups of Ni-preloaded and unloaded OPMF were analysed using Fourier Transform Infrared (FTIR) spectrometer (Perkin-Elmer 2000). To determine the phase of nickel species attached on the Ni-preloaded OPMF and its char, X-ray Diffraction (XRD) analysis were carried out using a Rigaku Ultima IV diffractometer $(\mathrm{Cu}$ Ka radiation, 40 $\mathrm{kV} / 40 \mathrm{~mA}$ ). The crystallite size of nickel species was determined based on the XRD data using Scherrer equation.

\section{Results and Discussion}

\subsection{Nickel adsorption onto OPMF}

OPMF with and without nickel addition were analysed using ICP-OES. No nickel was detected from the raw OPMF. After soaking with nickel nitrate solution and washing with distilled water, the biomass was found to contain $2.81 \mathrm{mg} / \mathrm{g}$ nickel. To further prove that nickel has successfully adsorbed onto OPMF, XRD analysis were carried out. Figure 2 shows the XRD spectrum of Ni-loaded OPMF and its char. The spectrum shows the peaks of various nickel nitrate $\left(\mathrm{Ni}\left(\mathrm{NO}_{3}\right)_{2}\right)$ phases at $2 \theta=22.19$, $26.94,50.49$, and 68.46. The XRD peak of nickel nitrate crystalline was obvious at $2 \theta=26.94$. A calculation using Scherrer equation suggests that the crystallite size of nickel nitrate was 55 $\mathrm{nm}$. The low XRD peak intensity also indicates good dispersion of nickel phases on its support [8]. FESEM and EDX analysis however could not detect the existence of nickel species on the surface of raw OPMF, implying that nickel does not adsorb on the OPMF surface but instead disperses well into the biomass matrix via ion exchange processes.

Figure 3 shows the FTIR spectra of $\mathrm{Ni}$ preloaded and unloaded OPMF. The peak at $3318 \mathrm{~cm}^{-1}$ indicates the presence of hydroxyl groups such as phenol and alcohol or due to the moisture content [9]. The peaks at 2920 and $2852 \mathrm{~cm}^{-1}$ represent asymmetric and symmetric C-H vibration and symmetric vibration of $\mathrm{CH}_{2}$ groups in cellulose belonging to the aromatic and alkyl compounds [10]. The peaks at 1740 and $1629 \mathrm{~cm}^{-1}$ are indicative of the $(\mathrm{C}=\mathrm{O})$

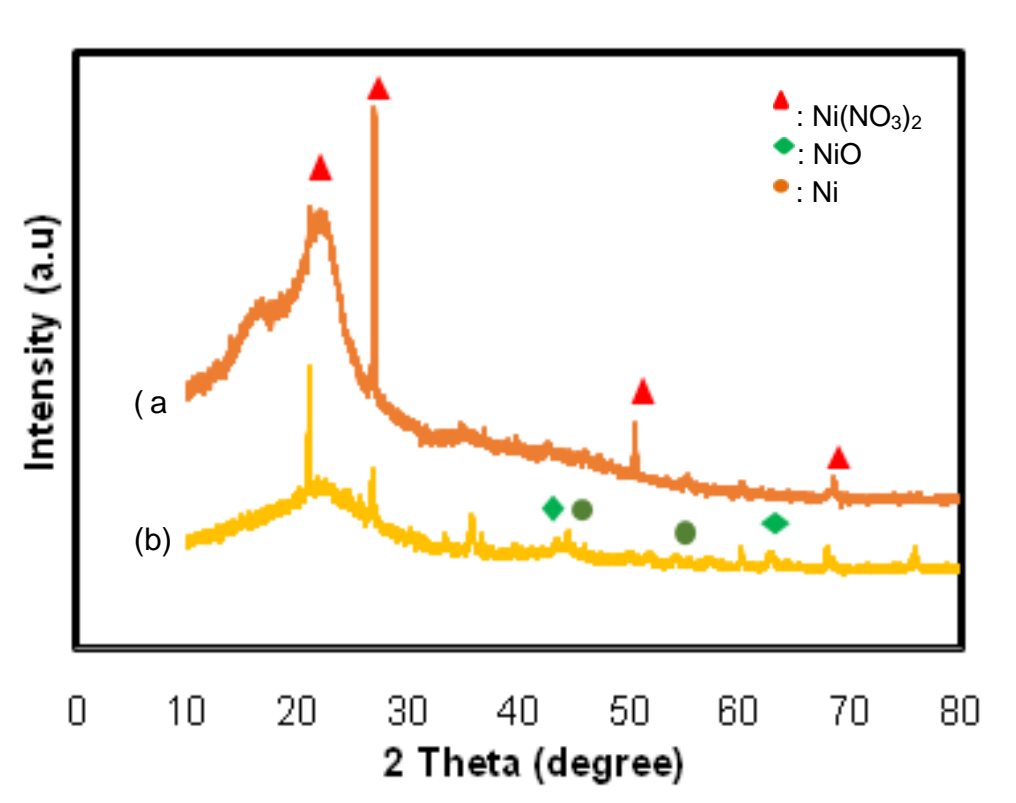

Figure 2. XRD spectra of the Ni-loaded OPMF (a) and its derived Ni-containing char (b) 
carbonyl stretching, representing ketone, aldehyde, carboxylic acid and ester groups [11]. The peak at $1032 \mathrm{~cm}^{-1}$ shows the vibration of CO-C (polysaccharide) and the presence of ethanol $(\mathrm{C}-\mathrm{OH})$. After soaking with nickel nitrate solution, all of the functional groups bands of the OPMF show some changes, especially the $-\mathrm{OH}$ stretching $\left(3318 \mathrm{~cm}^{-1}\right)$, suggesting the major attachment of $\mathrm{Ni}^{2+}$ was on the $-\mathrm{OH}$ groups. In agreement with other previous finding [12], other functional groups (carbonyl, carboxyl and $\mathrm{C}-\mathrm{O}-\mathrm{C}$ groups) were also found to participate in the binding of metal ions to the biomass.

As it was certain that nickel can be successfully loaded onto the OPMF, the effect of initial metal solution $\mathrm{pH}$ was then studied to optimise the loading of nickel. The $\mathrm{pH}$ of metal solution was adjusted between 2.0 to 8.0 by using $0.1 \mathrm{M} \mathrm{NaOH}$ and $0.1 \mathrm{M} \mathrm{HCl}$. The OPMF was soaked inside the $\mathrm{pH}$ adjusted nickel solution for $2 \mathrm{~h}$ with continuous stirring. The influence of initial nickel solution $\mathrm{pH}$ can be explained by considering the point of zero charge $\left(\mathrm{pH}_{\mathrm{pzc}}\right)$ of the OPMF. The importance of $\mathrm{pH}_{\mathrm{pzc}}$ is to determine the surface behaviour at which the surface of OPMF has a zero charge. It was determined from the point where the curve crosses the straight line that fits the points $\mathrm{pH}_{\text {initial }}=\mathrm{pH}_{\text {final }}$ [13]. Figure 4 shows that the point is at $\mathrm{pH} 6.17$. When the solution $\mathrm{pH}$ is higher than $\mathrm{pH}_{\mathrm{pzc}}$, the surface of adsorbent is negatively charged, thus the cation (metal ions, i.e., $\mathrm{Ni}^{2+}$ ) adsorption is favoured. The anion $(\mathrm{OH})$ adsorption, on the other hand, is favoured when the $\mathrm{pH}$ is lower than $\mathrm{pH}_{\mathrm{pzc}}$. In an acidic condition ( $\mathrm{pH}$ lower than $\mathrm{pH}_{\mathrm{pzc}}$ ), the nickel adsorption is low due to the high competition of $\mathrm{H}^{+}$ions in solution with

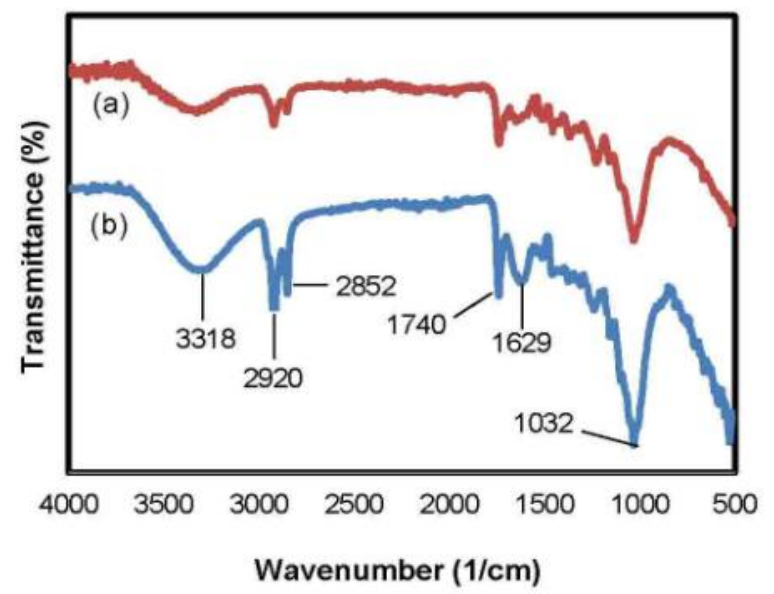

Figure 3. FTIR spectra of the OPMF with (a) and without (b) nickel addition predominant $\mathrm{Ni}\left(\mathrm{H}_{2} \mathrm{O}\right)_{6}{ }^{2+}$ species. The surface of OPMF below this $\mathrm{pH}_{\mathrm{pzc}}$ is positively charged, thus the electrostatic interaction of $\mathrm{Ni}\left(\mathrm{H}_{2} \mathrm{O}\right)_{6}{ }^{2+}$ is not so favourable [7].

$\mathrm{pH}$ of the solution is the most important parameter that affect the metal ions adsorption by influencing the adsorbent surface properties through functional group dissociation, surface charge and degree of ionisation. Figure 5 shows that nickel uptake increases with nickel solution $\mathrm{pH}$. At lower $\mathrm{pH}$, higher content of $\mathrm{H}^{+}$ions causes greater competition with positively charged $\mathrm{Ni}^{2+}$, thus restricts it to approach the active sites on the OPMF due to the repulsion [14]. The uptake of $\mathrm{Ni}^{2+}$ at higher $\mathrm{pH}$ is higher due to the lower concentration of $\mathrm{H}^{+}$, thus make it easy for the $\mathrm{Ni}^{2+}$ to occupy the active sites of the biomass. The negatively charged OPMF surface at higher $\mathrm{pH}$ and the increase of negative functional groups attract more cation of $\mathrm{Ni}^{2+}$ for binding, thus results in higher nickel loading. The formation of polymeric nickel species like tetramere $\left[\mathrm{Ni}_{4}(\mathrm{OH})_{4}{ }^{4+}\right]$ hydroxonickel at higher $\mathrm{pH}$ also contributed to the higher nickel adsorption [15]. For this reason, the experiment was not conducted beyond $\mathrm{pH}$ 8.0.

\subsection{Air gasification of Ni-preloaded OPMF}

Air gasification experiments were carried out on the Ni-preloaded and unloaded OPMF within the temperature range of $750-950{ }^{\circ} \mathrm{C}$. The effect of nickel addition on the air gasification of OPMF was visibly evident from the appearance of the reactor outlet. The inner wall of the silicon tube connecting the reactor and the dreschel bottles turned into black colour when OPMF without nickel addition was

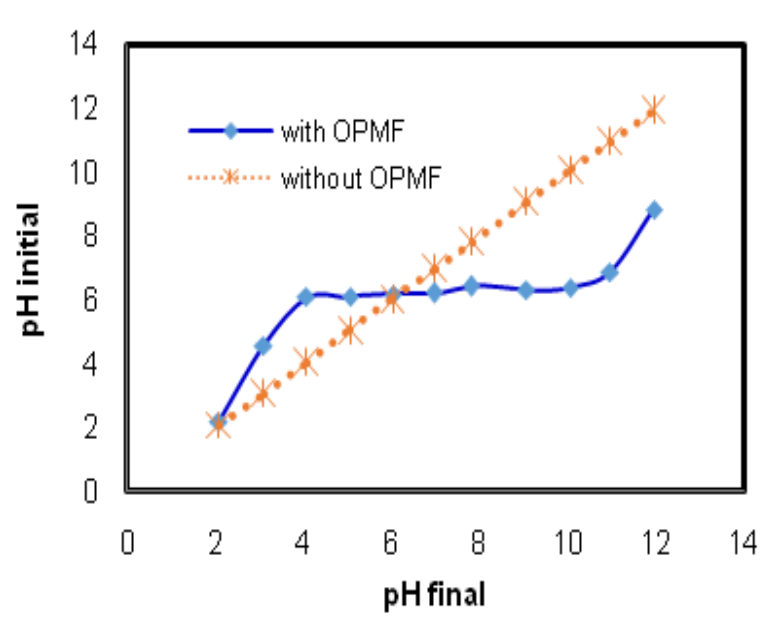

Figure 4. Point of zero charge of the oil palm mesocarp fiber 
gasified. In comparison, during the gasification of Ni-preloaded OPMF, the colour of silicon tube only turned to light yellowish brown.

Figure 6 contrasts the colour of methanolchloroform mixture (used to trap tar) from the air gasification of Ni-preloaded and unloaded OPMF at $900{ }^{\circ} \mathrm{C}$. As can be seen, the addition of nickel on OPMF produced a much lighter colour of tar solution. Calculations show that $\mathrm{Ni}$ preloaded OPMF yields only $0.2 \%$ gasification tar at $900{ }^{\circ} \mathrm{C}$, while the unloaded OPMF yields $0.8 \%$ tar (i.e. $75 \%$ difference) under the same reaction conditions.

Figure 7 shows the composition of gaseous products $\left(\mathrm{H}_{2}, \mathrm{CO}_{2}, \mathrm{CH}_{4}\right.$ and $\left.\mathrm{CO}\right)$ from the gasification of Ni preloaded and unloaded OPMF. At all temperatures studied, the addition of nickel gives positive results for the production of $\mathrm{CO}, \mathrm{H}_{2}$ and $\mathrm{CH}_{4}$. The production of the unwanted $\mathrm{CO}_{2}$, on the other hand, was found to be lower with than without nickel addition at most of the temperatures. Data in Figure 7 also show that while the production of $\mathrm{H}_{2}, \mathrm{CH}_{4}, \mathrm{CO}$ and $\mathrm{CO}_{2}$ continue to increase with increasing temperature in the gasification of Ni-loaded OPMF, the concentration of light gases (especially $\mathrm{H}_{2}$ and $\mathrm{CH}_{4}$ ) in the gasification of unloaded OPMF only increases initially with increasing temperature but decreases beyond the temperature of $850{ }^{\circ} \mathrm{C}$. The following discussions provide explanations for the above experimental results and observations.

Upon exposure of fed biomass at high temperature inside the reactor, water in the form of moisture quickly release from the biomass as steam. Further exposure of biomass at high temperature breaks its polymer chains, resulting in the release/formation of light gases $\left(\mathrm{H}_{2}\right.$, $\mathrm{CO}, \mathrm{CO}_{2}, \mathrm{CH}_{4}$ ), hydrocarbon volatiles (tar), gas phase radicals and solid carbon material (char)

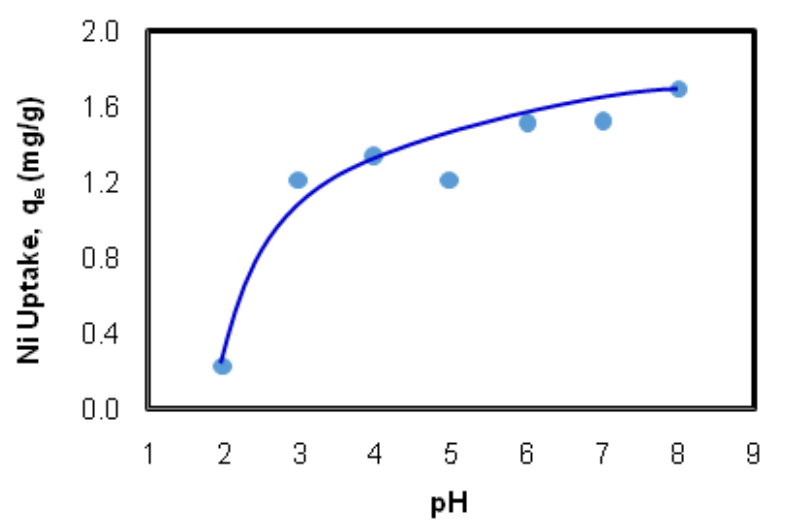

Figure 5. Effect of initial $\mathrm{pH}$ on nickel adsorption by the OPMF
(Equation 1). Various gas-gas and gas-solid reactions, which are briefly discussed below, take place upon the decomposition of biomass.

Hydrocarbon volatiles may, within or outside of biomass particles, react with oxygen of the air (Equations 3 and 4) and other biomass decomposition products (Equations 5 and 6), or undergo thermal cracking (Equation 7), to generate light gases via numerous complicated gas phase radical reaction mechanisms. The char vapour contacts cause some tar to adsorb and ultimately dehydrogenate to form coke on the char surface. Oxidation (Equations 8 and 9) and gasification (Equations 10-12) of coke and char may then take place to result in the formation of additional light gases.

Biomass decomposition:

Biomass $\rightarrow$ tar $+\mathrm{H}_{2} \mathrm{O}+$ light gas + char +radicals

Reactions of tar in the gas phase $\left(\mathrm{C}_{n} \mathrm{H}_{m}\right.$ represents tar):

$$
\begin{aligned}
& \mathrm{C}_{\mathrm{n}} \mathrm{H}_{\mathrm{m}}+(\mathrm{n} / 2) \mathrm{O}_{2} \rightarrow \mathrm{nCO}+(\mathrm{m} / 2) \mathrm{H}_{2} \\
& \mathrm{C}_{\mathrm{n}} \mathrm{H}_{\mathrm{m}}+(2 \mathrm{n}+\mathrm{m}) / 2 \mathrm{O}_{2} \rightarrow(\mathrm{m} / 2) \mathrm{H}_{2} \mathrm{O}+\mathrm{nCO} \\
& \mathrm{C}_{\mathrm{n}} \mathrm{H}_{\mathrm{m}}+\mathrm{nH}_{2} \mathrm{O} \rightarrow(\mathrm{m} / 2+\mathrm{n}) \mathrm{H}_{2}+\mathrm{nCO} \\
& \mathrm{C}_{\mathrm{n}} \mathrm{H}_{\mathrm{m}}+\mathrm{nCO}_{2} \rightarrow(\mathrm{m} / 2) \mathrm{H}_{2}+2 \mathrm{nCO} \\
& \mathrm{C}_{\mathrm{n}} \mathrm{H}_{\mathrm{m}} \rightarrow(\mathrm{m} / 4) \mathrm{CH}_{4}+(\mathrm{n}-\mathrm{m} / 4) \mathrm{C}
\end{aligned}
$$

Carbon oxidation:

$$
\begin{aligned}
& \mathrm{C}+1 / 2 \mathrm{O}_{2} \rightarrow \mathrm{CO} \\
& \mathrm{C}+\mathrm{O}_{2} \rightarrow \mathrm{CO}_{2}
\end{aligned}
$$

Carbon gasification:

$$
\begin{aligned}
& \mathrm{C}+\mathrm{CO}_{2} \rightarrow 2 \mathrm{CO} \\
& \mathrm{C}+\mathrm{H}_{2} \mathrm{O} \rightarrow \mathrm{CO}+\mathrm{H}_{2} \\
& \mathrm{C}+2 \mathrm{H}_{2} \rightarrow \mathrm{CH}_{4}
\end{aligned}
$$

In the absence of catalyst and at a relatively low temperature $\left(<1000{ }^{\circ} \mathrm{C}\right)$, the extent of reac-

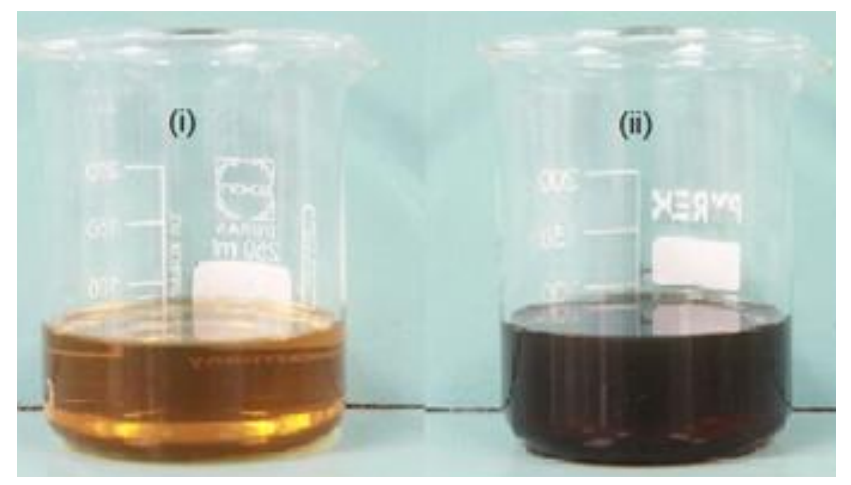

Figure 6. Comparison of tar solution from the gasification of Ni-loaded OPMF (i) and unloadedOPMF (ii) at $900^{\circ} \mathrm{C}$ 
tions (Equations 3-7) is rather limited. Significant portion of hydrocarbon volatiles remain unconverted until they exit the reactor. This may cause high tar content (Figure 6) and low syngas concentration (Figure 7) in the outlet gas, as in the case of air gasification of unloaded OPMF in this study. Without extensive reactions in the gas phase, the generation of light gases during the gasification of unloaded OPMF relies largely on the oxidation and gasification of char (Equations 8-12). However, since air is used as the gasifying agent, $\mathrm{O}_{2}$ presents at much higher concentration than $\mathrm{CO}_{2}, \mathrm{H}_{2} \mathrm{O}$ and $\mathrm{H}_{2}$ inside the char reaction zone of the reactor. It is also important to note that char reacts at a faster rate with $\mathrm{O}_{2}$ than with other gasifying molecules. Therefore, in our experimental conditions, reactions (Equations 8 and 9) are favoured more than reactions (Equations 10-12). This explains why char oxidation products (especially $\mathrm{CO}_{2}$ ) are much more dominant than char gasification products in the gasification of untreated OPMF (Figure 7).
The effect of temperature on the gasification of unloaded OPMF, on the other hand, can be explained by considering the influence of the alkali and alkaline earth metals (AAEM) naturally present in biomass. It has long been recognised that some inherent AAEM species (e.g. $\mathrm{Na}, \mathrm{K}, \mathrm{Mg}$, and $\mathrm{Ca}$ ) remain attached with char at nano-scale dispersion upon the decomposition of biomass [16]. The presence of AAEM in char brings two important consequences. Firstly, AAEM may catalyse the destruction of tar through coke formation and subsequent coke gasification/oxidation [17]. Secondly, the concentration of AAEM in char determines the reactivity of char towards oxidation and gasification reactions [18]. Nevertheless, it is also well known that AAEM may also volatilise from the char especially at high temperature [19]. The loss of AAEM species will definitely reduce tar destruction activity on char as well as char oxidation/gasification reactivity. We believe that significant volatilisation of AAEM took place in our study at temperatures above $850{ }^{\circ} \mathrm{C}$, thus responsible for the decrease in
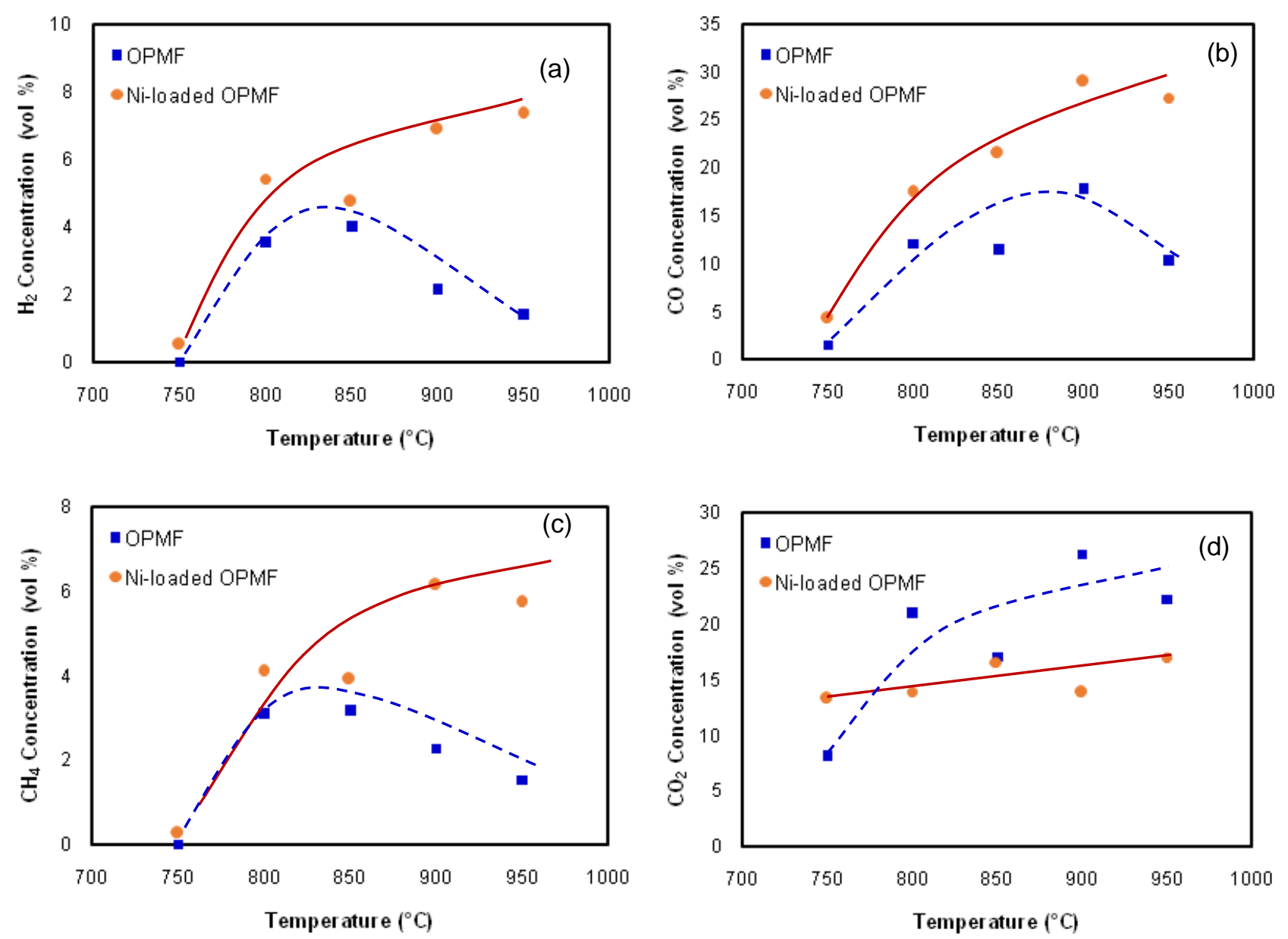

Figure 7. Concentrations of $\mathrm{H}_{2}(\mathrm{a}), \mathrm{CO}(\mathrm{b}), \mathrm{CH}_{4}$ (c) and $\mathrm{CO}_{2}$ (d) from the gasification of Ni-loaded and unloaded OPMF within $750-950^{\circ} \mathrm{C}$ 
light gases production (especially $\mathrm{H}_{2}$ and $\mathrm{CH}_{4}$ ) beyond $850{ }^{\circ} \mathrm{C}$ in the gasification of unloaded OPMF.

During the gasification of $\mathrm{Ni}$-preloaded OPMF, the nascent volatiles from the decomposition of biomass immediately make contact with nickel species on OPMF to results in the transformation of $\mathrm{Ni}\left(\mathrm{NO}_{3}\right)_{2}$ to $\mathrm{NiO}$ and ultimately to $\mathrm{Ni}$. The transformation of nickel phases is manifested by comparing the XRD spectrum of Ni-preloaded OPMF and that of the resulting Ni-loaded char (Figure 2). It is believed that series of in situ oxidation-reduction cycles takes place on $\mathrm{Ni} / \mathrm{NiO}_{\mathrm{x}}$ on OPMF/char during the gasification of $\mathrm{Ni}$ preloaded OPMF due to continuous exposure of $\mathrm{Ni} / \mathrm{NiO}_{\mathrm{x}}$ to various reducing and oxidising species inside the reactor.

Several studies have shown that nickel has high catalytic activity for tar cracking [1, 2021 . Nickel catalysts are also widely used in industry for the reforming/partial oxidation of light hydrocarbons and they are often described as having serious deactivation problems due to coke formation. In this study, the contact between volatiles and $\mathrm{Ni} / \mathrm{NiO}_{\mathrm{x}}$ on char promotes the catalytic cracking of heavy hydrocarbon into lighter components as well as coke formation on nickel surface. The reactions between coke with oxidation / gasification reactants (Equations 8 and 9) refresh the nickel surface while at the same time eliminating the deactivation of nickel surface and producing light gases products. Apart from catalysing tar destruction, nickel may also catalyse the dissociation of steam and $\mathrm{O}_{2}$ to form reactive free radicals (i.e. $\mathrm{H}, \mathrm{O}$, and $\mathrm{OH}$ ) on its surface. A shown in the past studies [22-23], radicals formed on the nickel surface may desorb from the catalyst surface to increase the concentration of radicals in the gas phase. The desorption of radicals, including those generated from the dissociation of

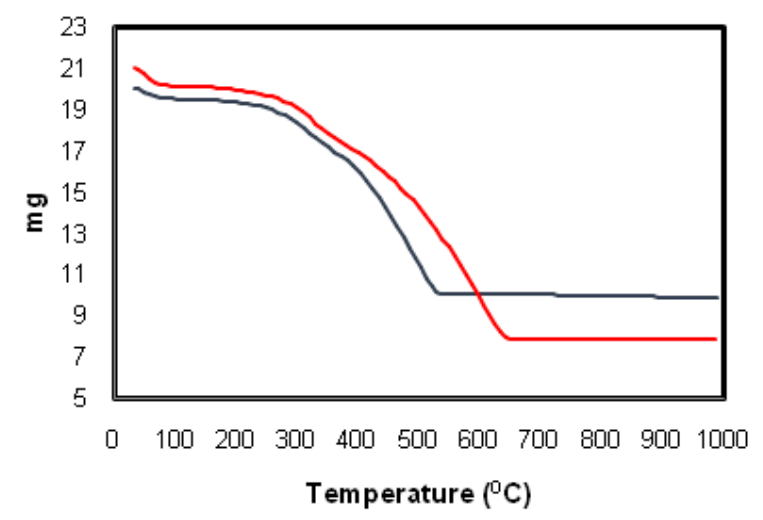

$\mathrm{O}_{2} /$ steam and the cracking of tar on nickel, supply additional gas-phase radicals to enhance the radical-driven homogeneous reactions to reform high molecular weight hydrocarbons into light gases. The combined actions of nickel discussed above contributed to the positive effects of nickel addition on OPMF towards the reduction of tar (Figure 6) and the higher production of $\mathrm{CO}, \mathrm{H}_{2}$ and $\mathrm{CH}_{4}$ (Figure 7).

Unlike the gasification of unloaded OPMF, where $\mathrm{CO}_{2}$ dominates the composition of gaseous products, our results show that $\mathrm{CO}$ was the major gaseous product in the gasification of $\mathrm{Ni}$ preloaded OPMF. The concentrations of $\mathrm{H}_{2}$ and $\mathrm{CH}_{4}$ were significantly higher and $\mathrm{CO}_{2}$ concentration was much lower, especially at high temperatures, if compared to the gasification of unloaded OPMF. It must be noted that $\mathrm{Ni}$ preloaded OPMF was prepared by soaking OPMF in the aqueous nickel solution. During soaking and subsequent washing of OPMF, significant amount of AAEM may have leached out of biomass, resulting in the low concentration of AAEM in the char formed from the gasification of Ni-preloaded OPMF. Some radicals generated on nickel surface, either from the cracking of tar or the dissociation of $\mathrm{O}_{2} /$ steam, may have migrated to the char surface to result in the alteration of char structure to eventually decrease the reactivity of char. This possibility has been discussed in great details by other researchers before [24].

The low reactivity of Ni-containing char due to the low concentration of AAEM and the changes in char structure, therefore, limits the contribution of char oxidation in the gasification of Ni-preloaded OPMF. To further prove this speculation, both unloaded and $\mathrm{Ni}$ preloaded OPMF chars were analysed using TGA in an air atmosphere. TGA results in Figure 8 confirm that the reactivity of unloaded

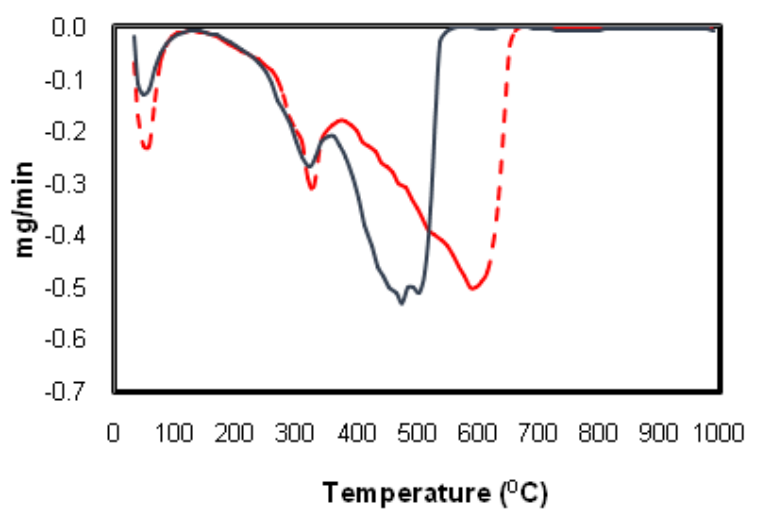

Figure 8. Results of TGA analysis under air atmosphere for the Ni-containing char from the gasification of Ni-loaded $\mathrm{OPMF}$ at $900{ }^{\circ} \mathrm{C}$ and char from the gasification of unloaded $\mathrm{OPMF}$ at $900{ }^{\circ} \mathrm{C}$ 
OPMF char towards oxidation with air is higher than the Ni-preloaded OPMF char. It can therefore be concluded that the production of syngas in the gasification of Ni-preloaded OPMF was contributed almost exclusively via the destruction of tar not the gasification/oxidation of char. The low reactivity of $\mathrm{Ni}$ containing char suggests that the unconverted chars from the gasification of $\mathrm{Ni}$-preloaded OPMF are suitable to be re-utilised as a catalyst. This will be further discussed in the next section.

\subsection{Potential re-utilisation of $\mathrm{Ni}$ - containing char as a catalyst}

To evaluate the potential re-utilisation of Ni-containing char produced from the gasification of $\mathrm{Ni}$ preloaded OPMF as a catalyst, especially in the secondary clean-up of biomass gasification tar, the catalytic steam reforming was carried out using benzene and toluene as the tar model compounds. Steam reforming was chosen as it was described by many [21, 25] as the best way to destroy tar components from both technical and economic points of view. The residual chars from previous (Section 3.2) air gasification experiments at $900{ }^{\circ} \mathrm{C}$ were used as the catalyst. Figure 9 compares the syngas compositions from benzene and toluene reforming at $850{ }^{\circ} \mathrm{C}$ in the absence and presence of catalyst (char and Ni-containing char as catalyst).

Reasonable amount of syngas was produced in the absence of catalyst, suggesting high contribution of thermal cracking of benzene and toluene at the investigated temperature. Various possible reactions occurring during the steam reforming of toluene and benzene have

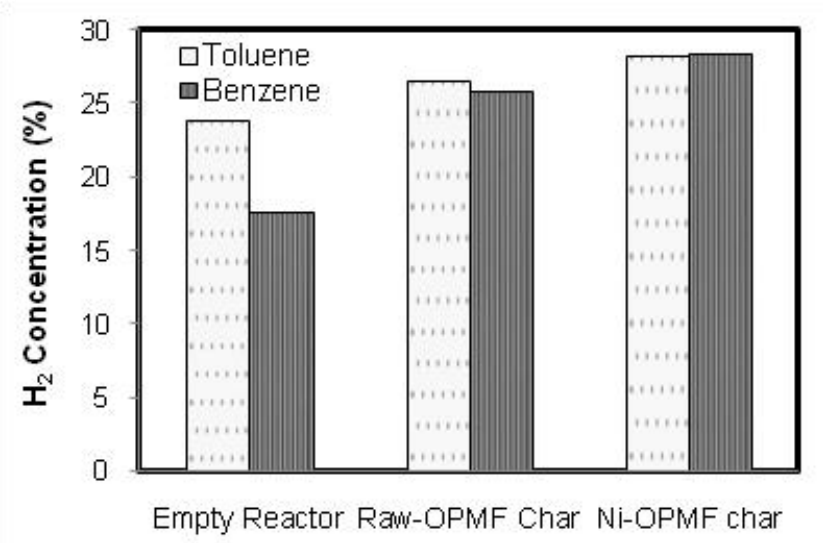

been described by others [21, 25]. We do not intend to discuss this subject in details as the steam reforming of tar/tar model compounds deserve a publication by its own and this will be the subject of our future research and publication. Nevertheless, in this study as is shown in Figure 9, char shows some catalytic contributions to the syngas production especially in the steam reforming of benzene. The catalytic activity of $\mathrm{Ni}$ containing char was even higher than char for both toluene and benzene steam reforming. Our results, therefore, suggest that the unconsumed $\mathrm{Ni}$ containing chars from the gasification of $\mathrm{Ni}$ loaded OPMF have great potentials to be reutilised as a catalyst to further catalyse the reduction of tar either in the secondary tar reduction process or in the primary gasification process.

\section{Conclusions}

Our study demonstrates that the gasification of $\mathrm{Ni}$-preloaded biomass is an attractive approach to produce clean syngas. Nickel can disperse very well on the biomass via ion-exchange mechanisms involving various functional groups. The addition of $\mathrm{Ni}$ improves significantly the reduction of tar and increase tremendously the production of syngas in the air gasification of biomass. While the production of light gases in the absence of $\mathrm{Ni}$ relies largely on the gasification/oxidation of char, the presence of $\mathrm{Ni}$ enhances the conversion of tar components via gas-gas and gas-solid reactions. The unconverted Nicontaining char exhibits high potential for the re-utilisation as a catalyst.

Figure 9. $\mathrm{CO}$ and $\mathrm{H}_{2}$ concentrations from the steam reforming of benzene and toluene at $850{ }^{\circ} \mathrm{C}$ in the empty reactor, in the presence of char as a catalyst and in the presence of $\mathrm{Ni}$-containing char as a catalyst

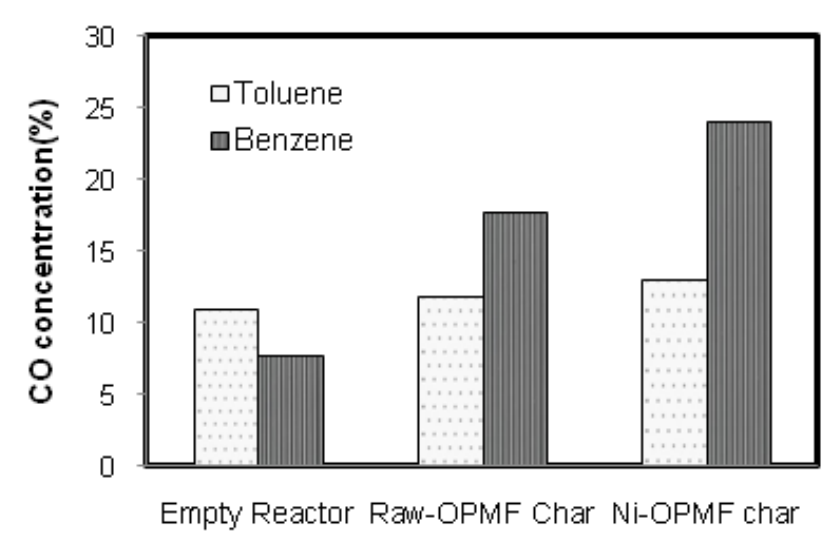




\section{Acknowledgement}

The authors greatly acknowledge the financial support of this study from the Malaysian Ministry of Higher Education (MOHE) via the Fundamental Research Grant Scheme (FRGS/1/2013/TK07/UITM/02/2).

\section{References}

[1] Abu El-Rub, Z., Bramer, E.A., Brem, G. (2004). Review of catalysts for tar elimination in biomass gasification processes. Industrial and Engineering Chemistry Research, 43(22): 6911-6919.

[2] Sutton, D., Kelleher, B., Ross, J.R.H. (2001). Review of literature on catalysts for biomass gasification. Fuel Processing Technology, 73(3): 155-173.

[3] Yung, M.M., Jablonski, W.S., Magrini-Bair, K.A. (2009). Review of catalytic conditioning of biomass-derived syngas. Energy \& Fuels, 23: 1874-1887.

[4] Devi, L., Ptasinski, K.J., Janssen, F.J.J.G. (2003). A review of the primary measures for tar elimination in biomass gasification processes. Biomass and Bioenergy, 24(2): 125-140.

[5] Zhou, H., Cao, Y., Zhao, H., Liu, H., Pan, W.P. (2008). Investigation of $\mathrm{H}_{2} \mathrm{O}$ and $\mathrm{CO}_{2}$ reforming and partial oxidation of methane: catalytic effects of coal char and coal ash. Energy \& Fuels, 22(4): 2341-2345.

[6] Syed-Hassan, S.S.A., Nor-Azemi, S.N.I., Fuadi, F.A. (2014). Adsorption and dispersion of nickel on oil palm mesocarp fiber. Chemical Engineering Transactions, 37: 709-714.

[7] Richardson, Y., Blin, J., Volle, G., Motuzas, J., Julbe, A. (2010). In situ generation of $\mathrm{Ni}$ metal nanoparticles as catalyst for $\mathrm{H}_{2}$-rich syngas production from biomass gasification. Applied Catalysis A: General, 382(2): 220-230.

[8] Lu, Y., Li, S., Guo, L. (2013). Hydrogen production by supercritical water gasification of glucose with $\mathrm{Ni} / \mathrm{CeO}_{2} / \mathrm{Al}_{2} \mathrm{O}_{3}$ : Effect of Ce loading. Fuel 103: 193-199.

[9] Qian, K., Kumar, A., Patil, K., Bellmer, D., Wang, D., Yuan, W., Huhnke, R. (2013). Effects of biomass feedstocks and gasification conditions on the physiochemical properties of char. Energy, 6: 3972-3986.

[10] Abnisa, F., Arami-Niya, A., Daud, W.M.A.W., Sahu, J.N. (2013). Characterization of bio-oil and bio-char from pyrolysis of palm oil wastes. BioEnergy Research, 6(2): 830-840.

[11] Cantrell, K.B., Hunt, P.G., Uchimiya, M., Novak, J.M., Ro, K.S. Impact of pyrolysis temperature and manure source on physicochemi- cal characteristics of biochar. Bioresource Technology, 107: 419-428.

[12] Gerola, G.P., Boas, N.V., Caetano, J., Tarley, C.R.T., Gonçalves, A.C., Dragunski, D.C. (2013). Utilization of passion fruit skin byproduct as lead(II) ion biosorbent. Water, Air \& Soil Pollution, 224: 1-11.

[13] Xiao, B., Thomas, K.M. (2005). Adsorption of aqueous metal ions on oxygen and nitrogen functionalized nanoporous activated carbons. Langmuir, 21(9): 3892-3902.

[14] Wahab, M.A., Jellali, S., Jedidi, N. (2010). Effect of temperature and $\mathrm{pH}$ on the biosorption of ammonium onto Posidoniaoceanica fibers: equilibrium, and kinetic modeling studies. Bioresource Technology. 10(22): 8606-8615.

[15] Domazetis, G., Liesegang, J., James, B.D. (2005). Studies of inorganics added to lowrank coals for catalytic gasification. Fuel Processing Technology, 86: 463-486.

[16] Widayatno, W.B., Guan, G., Rizkiana, J., Hao, X., Wang, Z., Samart, C., Abudula, A. (2014). Steam reforming of tar derived from Fallopia Japonica stem over its own chars prepared at different conditions. Fuel, 132: 204-210.

[17] Zolin, A., Jensen, A., Jensen, P.A., Frandsen, F., Dam-Johansen, K. (2001). The influence of inorganic materials on the thermal deactivation of fuel chars. Energy \& Fuels,15(5): 110122.

[18] Mitsuoka, K., Hayashi, S., Amano, H., Kayahara, K., Sasaoaka, E., Uddin, M.A. (2011). Gasification of woody biomass char with $\mathrm{CO}_{2}$ : the catalytic effects of $\mathrm{K}$ and $\mathrm{Ca}$ species on char gasification reactivity. Fuel Processing Technology, 92(1): 26-31.

[19] Long, J., Song, H., Jun, X., Sheng, S., Lunshi, S., Kai, X., Yao, Y. (2012). Release characteristics of alkali and alkaline earth metallic species during biomass pyrolysis and steam gasification process. Bioresource Technology, 116: 278-284.

[20] Guan, G., Chen, G., Kasai, Y., Lim, E.W.C., Hao, X., Kaewpanha, M., Abuliti, A., Fushimi, C., Tsutsumi, A. (2012). Catalytic steam reforming of biomass tar over iron- or nickel based catalyst supported on calcined scallop shell. Applied Catalysis B: Environmental, 115-116: 159-168.

[21] Zhang, R., Wang, Y., Brown, R.C. (2007). Steam reforming of tar compounds over $\mathrm{Ni} /$ olivine catalysts doped with $\mathrm{CeO}_{2}$. Energy Conversion and Management, 48: 68-77. 
[22] Syed-Hassan, S.S.A., Lee, W.J., Li, C.-Z. (2009). Positive and negative catalytic effects of a nickel mesh catalyst for the partial oxidation of ethane. Chemical Engineering Journal, 147(2-3): 307-315.

[23] Syed-Hassan, S.S.A., Li C.-Z. (2011). Catalytic oxidation of ethane with oxygen using fluidised nanoparticle $\mathrm{NiO}$ catalyst. Applied Catalysis A: General, 405(1-2): 166-174.
[24] Chen, T., Zhang, Y., Wang, H., Lu, W., Zhou, Z., Zhang, Y., Ren, L. (2014). Influence of pyrolysis temperature on characteristics and heavy metal adsorptive performance of biochar derived from municipal sewage sludge. Bioresource Technology, 164: 47-54.

[25] Park, H.J., Park,S. H.,Sohn,J. M., Park, J., Jeon, J.-K., Kim, S.-S., Park,Y.-K. (2010). Steam reforming of biomass gasification tar using benzene as a model compound over various $\mathrm{Ni}$ supported metal oxide catalysts. Bioresource Technology, 101(1): 101-103. 